\title{
Amorphous alloy reinforced Whipple shield structure
}

\author{
X. Huang ${ }^{a}$, Z. Ling ${ }^{a}$, Z.D. Liu ${ }^{\text {b }}$, H.S. Zhang ${ }^{\text {a }}$, L.H. Dai ${ }^{\text {a,c,* }}$

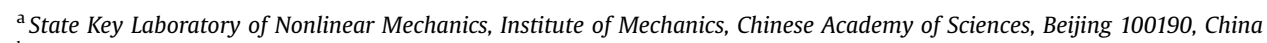 \\ ${ }^{\mathrm{b}}$ Key Laboratory of Condition Monitoring and Control for Power Plant Equipment of Ministry of Education, North China Electric Power University, Beijing 102206, China \\ ${ }^{\mathrm{c}}$ State Key Laboratory of Explosion Science and Technology, Beijing Institute of Technology, Beijing 100081, China
}

\section{A R T I C L E I N F O}

\section{Article history:}

Received 2 May 2011

Received in revised form

26 August 2011

Accepted 4 November 2011

Available online 15 November 2011

\section{Keywords:}

Hypervelocity impact

Amorphous alloy

Metallic glass

Whipple shield

\begin{abstract}
A B S T R A C T
In this paper, a new concept space shield structure, namely amorphous alloy reinforced Whipple shield structure, is proposed. A series of experiments have been performed on this new Whipple shield structure which consists of an amorphous alloy reinforced bumper and an LY12 Al (similar to $2024 \mathrm{Al}$ alloy) rear wall using two-stage light-gas gun at impact velocities of $3.5 \mathrm{~km} / \mathrm{s}$ and $5.5 \mathrm{~km} / \mathrm{s}$. Damages including penetration hole in the front bumper and craters on the rear wall have been studied, and it is found that the protective capability of Whipple shield was improved by replacing LY12 Al alloy bumper with Fe-based amorphous alloy reinforced bumper, especially at low impact velocity of $3.5 \mathrm{~km} / \mathrm{s}$. A dimensional analysis of the parameters involved in the hypervelocity impact indicates that the coating material with higher density, lower specific heat and not very high melting temperature is helpful for better performance of the new shields. Wave propagation in the projectile and bumper is discussed, and the shock wave strength and temperature rise are calculated, it is found that the amorphous alloy reinforced bumper can produce higher shock pressures and induce higher temperature rise in the projectile. Thus, our preliminary research shows some positive indications that the new Whipple shield structure may provide higher protection level than the traditional one.
\end{abstract}

(c) 2011 Elsevier Ltd. All rights reserved.

\section{Introduction}

Whipple shield is a traditional protective structure which consists of a front bumper at some stand-off distance from a rear wall. It was first suggested by the noted astrophysicist Whipple [1], and now widely used to protect spacecraft against space debris. During the last few decades, a large amount of research was done on Whipple shield as a means of reducing the perforation threat of hypervelocity projectiles. It was shown that such a dual-wall configuration can provide significant increases in protective capability over equivalent single-wall structures [2,3]. Although innovative shield configurations such as stuffed Whipple shield [4] and Multiple-Shock shield [5] were developed during the last 20 years for further increase of protection performance, Whipple shield is still extensively adopted. In particular, this dual-wall system can be found on the International Space Station.

Previous studies have shown that the performance of Whipple shield is significantly influenced by its geometry configuration (e.g.

\footnotetext{
* Corresponding author. State Key Laboratory of Nonlinear Mechanics, Institute of Mechanics, Chinese Academy of Sciences, Beijing 100190, China.

E-mail address: lhdai@Inm.imech.ac.cn (L.H. Dai).
}

distance between the front bumper and the rear wall, thicknesses of the two sheets) and material properties (e.g. density, acoustic velocity, strength) [6-8], and the front bumper is always the key element because it determines the condition of projectile after initial impact [9]. So selecting proper material for the front bumper is important in the shield design process. The traditional bumper material used in Whipple shield is aluminum alloy for its high strength-to-weight ratio. But as the safety requirements become higher, new bumper materials such as composite materials, ceramic materials, metallic foams, and super alloys were studied [10-13], and the protection performance of the shields was gradually improved. However, for the weight and volume constraint, it is still a problem to protect the spacecraft effectively against space debris.

As an effort that is made to find new effective bumper materials, an amorphous alloy (also called as metallic glass) is studied in this work. Compared with the traditional aluminum alloy, amorphous alloys have greater advantages for their unique physical and mechanic properties [14-16]. The strength of amorphous alloys is extremely high, even approaches the theoretical limit. For Zr-based and $\mathrm{Cu}$-based amorphous alloys, the reported strength is about 2 GPa [17-19], while that is approximately $4 \mathrm{GPa}$ for Fe-based and 5 GPa for Co-based [20]. Moreover, the density of amorphous alloys 
is always slightly lower than that of their crystalline counterparts. As a result, the strength-to-weight ratio of amorphous alloys is several times higher than that of conventional crystalline alloys. For the $\mathrm{Fe}_{77} \mathrm{Si}_{19} \mathrm{~B}_{4}$ used in the present work, the strength is about $3 \mathrm{GPa}$ while that is $340 \mathrm{MPa}$ for LY12 Al. Although the density is about $7.2 \mathrm{~g} / \mathrm{cm}^{3}$ larger than $2.78 \mathrm{~g} / \mathrm{cm}^{3}$ of LY12 Al, the strength-to-weight ratio is 3 times higher than that of LY12 Al. Besides, the melting temperature of many amorphous alloys is not very high [21]. Usually, bumper material with lower melting temperature can reduce the probability of complete penetration, because melting of bumper can lead to smaller particle sizes in debris cloud [22,23]. For the $\mathrm{Fe}_{77} \mathrm{Si}_{19} \mathrm{~B}_{4}$ used in the present work, the melting temperature is $1198 \mathrm{~K}$ while that is $933 \mathrm{~K}$ for LY12 Al. Although the melting temperature is slightly higher, the specific heat is significantly less than that of LY12 Al, so it is easier for the material to melt. The advantages above indicate that the amorphous alloys are very suitable as the bumper material in Whipple shield.

In this work, we have proposed a new Whipple shield structure with an amorphous alloy reinforced bumper which is a doublelayer structure and is expected to decrease the weight and volume of shield system. In order to evaluate the performance of this new Whipple shield structure, several hypervelocity impact tests are conducted on Whipple shields with two different bumpers including the amorphous alloy reinforced bumper and a traditional monolithic LY12 Al bumper which is used as a comparison. The damage characteristics of the shields are carefully examined. For a further comparation of the two shields, a dimension analysis is carried out. Besides, wave propagation in the projectile and bumper is discussed, and the shock strength and temperature rise in the projectile are estimated.

\section{Material preparation}

The amorphous alloy reinforced bumper used in this work consists of a Fe-based amorphous alloy coating and an LY12 aluminum alloy substrate. The coating was deposited on the substrate by electro-thermal explosion spraying which is a new spraying method with lots of advantages such as high hardness, low porosity and good bonding [24]. The spray materials are amorphous $\mathrm{Fe}-\mathrm{Si}-\mathrm{B}$ ribbons of $50 \mu \mathrm{m}$ thickness, with the nominal composition of $\mathrm{Fe}_{77} \mathrm{Si}_{14} \mathrm{~B}_{9}$. The polished LY12 aluminum alloy with the thickness of $2.85 \mathrm{~mm}$ is used as the substrate. During the spraying process, the spray materials are heated to molten or gasification states by the instantaneous electrification and discharge of the metal conductor. As a result, the substrate is impacted successively by the molten droplets under shock wave and then the coating is produced on the surface of the substrate [25]. The thickness of the amorphous alloy coating is $0.15 \mathrm{~mm}$. And $\mathrm{X}$-Ray diffraction conducted on the coating indicated that the coating material is composed of large amount of the amorphous phase and small amount of the crystalline phase.

\section{Hypervelocity impact experiments}

The hypervelocity impact experiments were carried on a twostage light-gas gun at impact velocities of about $3.5 \mathrm{~km} / \mathrm{s}$ and $5.5 \mathrm{~km} / \mathrm{s}$. The experimental configuration is illustrated in Fig. 1a, and Fig. 1b shows the device which is used to assemble the plates of Whipple shield and witness panel. There are three parts in the experimental configuration: a spherical projectile the Whipple shield and a witness panel. The projectiles used were solid LY12 aluminum alloy spheres with the same diameter of $4 \mathrm{~mm}$. The new Whipple shield structure consists of an amorphous alloy reinforced bumper and an LY12 Al rear wall, while a monolithic LY12 Al bumper is used in traditional Whipple shield. The thicknesses of
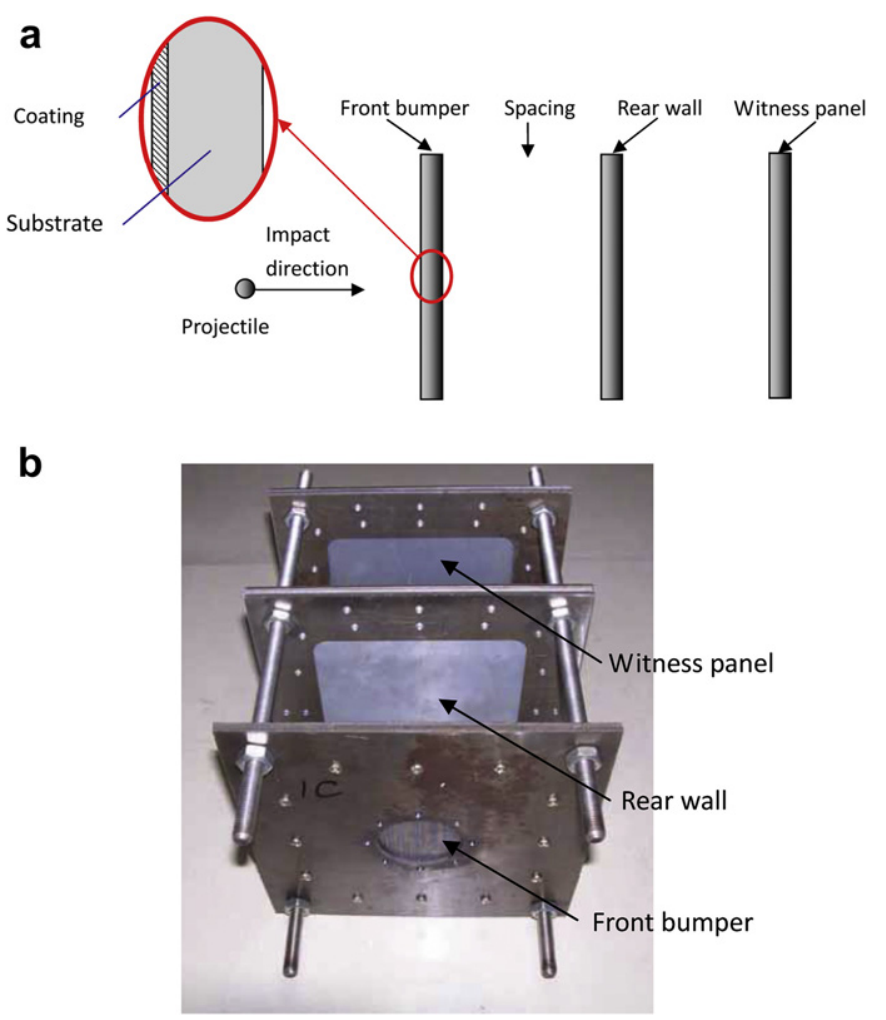

Fig. 1. (a) Experimental configuration. (b) Assemble device of plates.

both the front bumper and the LY12 Al rear wall in Whipple shield structure was held constant at $3 \mathrm{~mm}$. And the front bumper and the rear wall were separated by a constant distance of $100 \mathrm{~mm}$. An LY12 Al witness panel with thickness of $3 \mathrm{~mm}$ was placed at a distance of $100 \mathrm{~mm}$ behind the rear wall. Table 1 presents a summary of the hypervelocity impact test parameters. As a relatively young class of material, it is still very difficult to fabricate amorphous alloys of large size. Thus, only 4 tests were carried out in the present work.

\section{Results}

In each test, the front bumper of Whipple shield was penetrated by the sphere projectile, and a cloud of bumper and projectile debris that could contain solid fragments, liquid, or vapor particles was generated and impacted the rear wall, forming craters and bumps(spallation). No complete penetration or detached spallation was found on the rear wall in our tests. Thus we couldn't see any damage on the witness panel. From the observation of damage on the front bumpers and rear walls, the new shield made significantly better performance at low impact velocity of $3.5 \mathrm{~km} / \mathrm{s}$. But at impact velocity of $5.5 \mathrm{~km} / \mathrm{s}$, the difference between the performances of the two shields was not apparent. Although our

Table 1

Hypervelocity impact test parameters.

\begin{tabular}{|c|c|c|c|c|c|}
\hline \multicolumn{2}{|l|}{ Shot ID } & $1-1$ & $1-2$ & $2-1$ & $2-2$ \\
\hline \multicolumn{2}{|c|}{ Impact velocity $(\mathrm{km} / \mathrm{s})$} & 3.44 & 3.55 & 5.33 & 5.70 \\
\hline \multicolumn{2}{|c|}{ Projectile diameter $(\mathrm{mm})$} & 4 & 4 & 4 & 4 \\
\hline \multicolumn{2}{|c|}{ Bumper material } & LY12 Al & $\begin{array}{l}\mathrm{Fe}_{77} \mathrm{Si}_{19} \mathrm{~B}_{4} \\
+\mathrm{LY} 12 \mathrm{Al}\end{array}$ & LY12 Al & $\begin{array}{l}\mathrm{Fe}_{77} \mathrm{Si}_{19} \mathrm{~B}_{4} \\
+\mathrm{LY} 12 \mathrm{Al}\end{array}$ \\
\hline \multirow{3}{*}{$\begin{array}{l}\text { Bumper } \\
\text { thickness } \\
(\mathrm{mm})\end{array}$} & Total & 3 & 3 & 3 & 3 \\
\hline & Coating & 0 & 0.15 & 0 & 0.15 \\
\hline & Substrate & 3 & 2.85 & 3 & 2.85 \\
\hline \multicolumn{2}{|c|}{ Rear wall thickness (mm) } & 3 & 3 & 3 & 3 \\
\hline
\end{tabular}



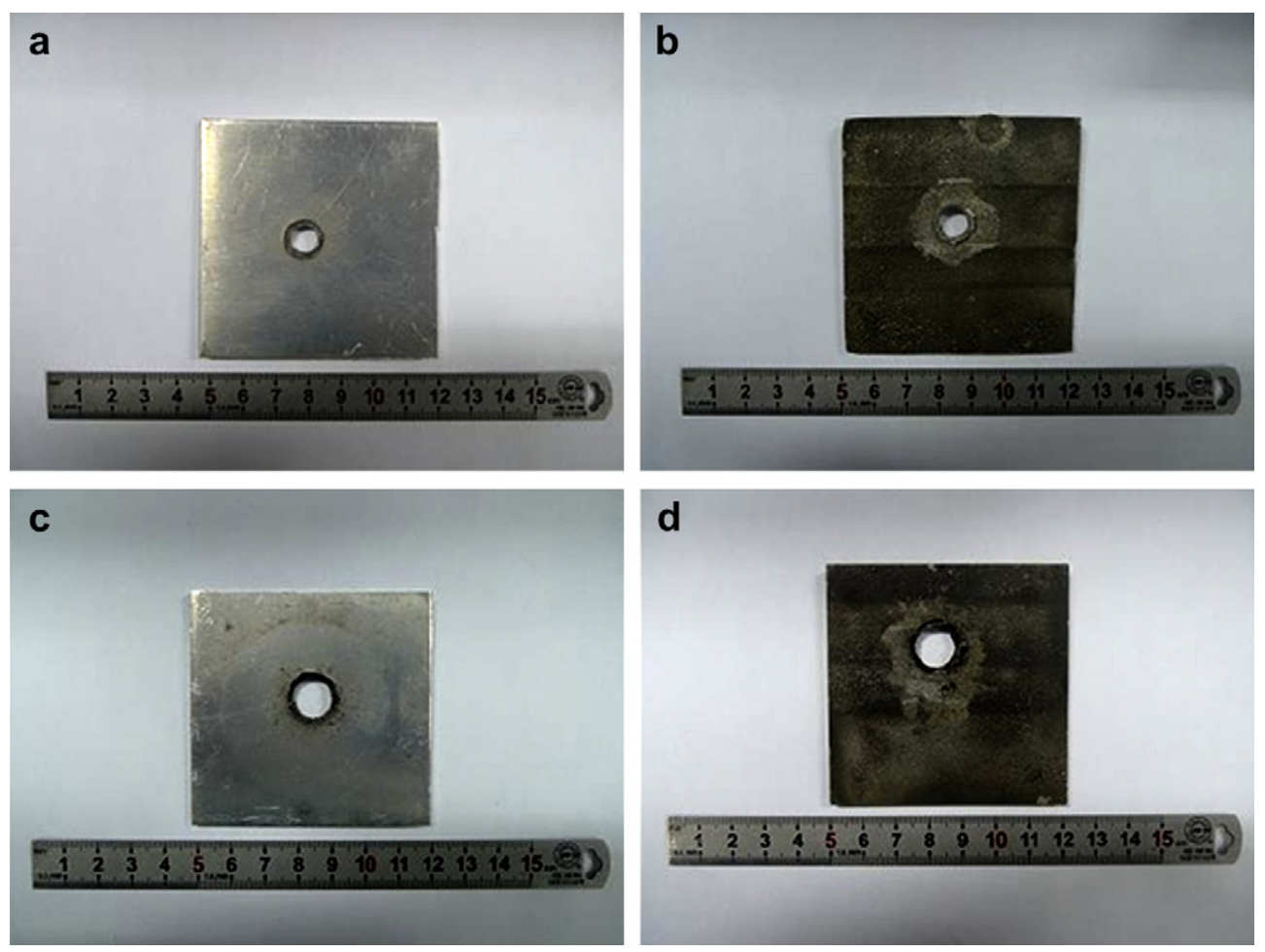

Fig. 2. Penetration hole in the front bumper: (a) $\mathrm{LY} 12 \mathrm{Al}, \mathrm{V}=3.44 \mathrm{~km} / \mathrm{s}$; (b) $\mathrm{Fe}_{77} \mathrm{Si}_{19} \mathrm{~B}_{4} / \mathrm{Al}, \mathrm{V}=3.55 \mathrm{~km} / \mathrm{s} ;(\mathrm{c}) \mathrm{LY} 12 \mathrm{Al}, \mathrm{V}=5.33 \mathrm{~km} / \mathrm{s}$; (d) $\mathrm{Fe}{ }_{77} \mathrm{Si}_{19} \mathrm{~B}_{4} / \mathrm{Al}, \mathrm{V}=5.70 \mathrm{~km} / \mathrm{s}$.

observation at impact velocity of $5.5 \mathrm{~km} / \mathrm{s}$ still showed that the new shield was slightly better, it was possibly induced by the variation of the impact velocities.

\subsection{Macroscopic damage morphology}

Fig. 2 shows the penetration hole in the front bumper of each test, and Table 2 presents the characteristics of the penetration holes. Compared with LY12 Al bumpers, holes produced in the Febased amorphous alloy reinforced bumpers are slightly larger and at the impact velocity of $3.5 \mathrm{~km} / \mathrm{s}$, there is curling formed around the hole of amorphous alloy reinforced bumper, while no obvious curling is found around the hole of LY12 Al bumper. Higher temperature rise of projectile and bumper material during the penetration progress in amorphous alloy reinforced bumper that induced thermal softening is the possible reason.

Fig. 3 shows the front side of rear wall in each test, and Table 3 presents the characteristics of craters on the rear walls. At the same impact velocity, the rear wall damage indicates that amorphous alloy reinforce bumpers made better performance in breaking up the projectile, especially at low impact velocities of $3.5 \mathrm{~km} / \mathrm{s}$. As is shown in Table 3, at impact velocity of $3.5 \mathrm{~km} / \mathrm{s}$, the max crater diameter and depth with LY12 Al bumper is larger than that with amorphous alloy reinforced bumper. But at impact velocity of $5.5 \mathrm{~km} / \mathrm{s}$, the max crater diameter and depth of both bumper materials are nearly the same.

Statistics on number of craters with different size are presented in Table 3. All the craters on the rear wall are divided to three

Table 2

The characteristics of penetration hole.

\begin{tabular}{lllll}
\hline Velocity $(\mathrm{km} / \mathrm{s})$ & 3.44 & 3.55 & 5.33 & 5.70 \\
\hline Bumper material & $\mathrm{LY12} \mathrm{Al}$ & $\mathrm{Fe}_{77} \mathrm{Si}_{19} \mathrm{~B}_{4} / \mathrm{Al}$ & $\mathrm{LY} 12 \mathrm{Al}$ & $\mathrm{Fe}_{77} \mathrm{Si}_{19} \mathrm{~B}_{4} / \mathrm{Al}$ \\
Diameter $(\mathrm{mm})$ & 8.0 & 8.5 & 11.5 & 12.0 \\
Curling & Not obvious & obvious & Not obvious & Not obvious \\
\hline
\end{tabular}

classes: (1) Main crater, which is obviously larger than other craters and is always in the centre of the crater zone; (2) Medium crater (diameter $>1 \mathrm{~mm}$ ); (3) Micro-crater (diameter $<1 \mathrm{~mm}$ ). It can be seen that there are more small craters on the rear wall with amorphous alloy reinforce bumper, while less big craters are found on it. At impact velocity of $3.5 \mathrm{~km} / \mathrm{s}$, there is 1 main crater on the rear wall with LY12 Al bumper, while there is no main crater but more medium craters and micro-craters found on the rear wall with amorphous alloy reinforced bumper. At impact velocity of $5.5 \mathrm{~km} / \mathrm{s}$, no main crater is found on both rear walls. There are about 438 medium craters on the rear wall with LY12 Al bumper, while there are less medium craters but more micro-craters found on the rear wall with amorphous alloy reinforced bumper.

Fig. 4 shows the back side of the rear wall in each test, and Table 4 presents the characteristics of bumps (spallation) and perforations. No complete penetration or detached spallation was found in our tests. Comparing the number and the size of bumps in each test, the spallation damage seams weaker on the back side of rear wall with amorphous reinforced bumpers.

\subsection{Microscopic damage morphology}

The microstructure of the penetration holes in front bumpers and the craters on the rear walls has been studied by SEM.

Fig. 5 shows the microstructures of the inner surfaces in the penetration holes. As the impact velocity increases from $3.5 \mathrm{~km} / \mathrm{s}$ to $5.5 \mathrm{~km} / \mathrm{s}$, the microstructures of the inner surface in the hole become more granular no matter the front bumper is LY12 Al bumper or amorphous alloy reinforced bumper. These microstructures indicate that as the impact velocity increases, the bumper material around the penetration hole was more severely fractured.

At the velocity of $3.5 \mathrm{~km} / \mathrm{s}$, the microstructures with amorphous alloy reinforced bumper shows some differences. Fig. 6 illustrates the melting zone of the inner surface found in the hole of 

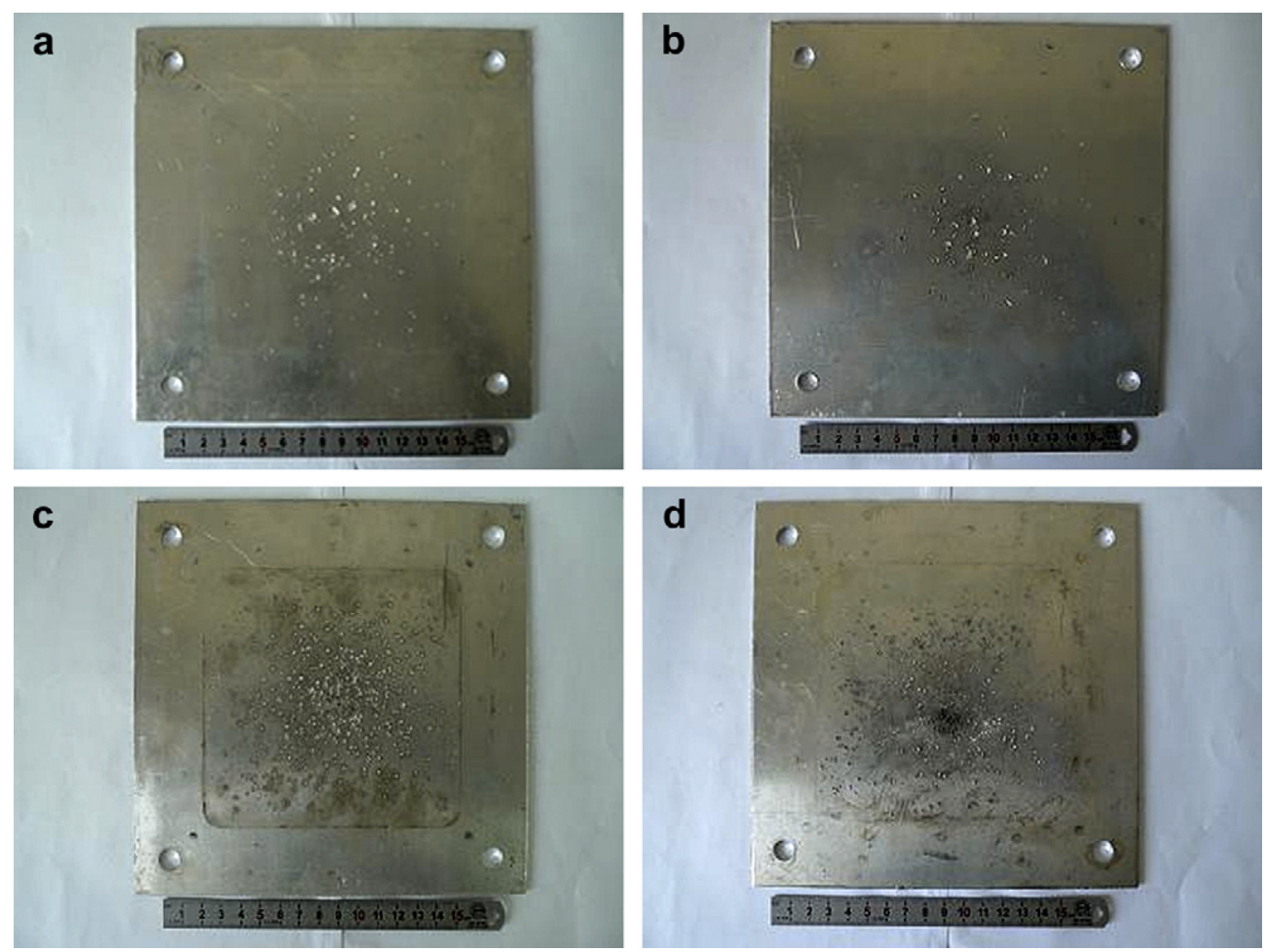

Fig. 3. Front side of the rear wall: (a) $\mathrm{LY} 12 \mathrm{Al}, \mathrm{V}=3.44 \mathrm{~km} / \mathrm{s}$; (b) $\mathrm{Fe}_{77} \mathrm{Si}_{19} \mathrm{~B}_{4} / \mathrm{Al}, \mathrm{V}=3.55 \mathrm{~km} / \mathrm{s}$; (c) $\mathrm{LY} 12 \mathrm{Al}, \mathrm{V}=5.33 \mathrm{~km} / \mathrm{s}$; (d) $\mathrm{Fe}{ }_{77} \mathrm{Si}{ }_{19} \mathrm{~B}_{4} / \mathrm{Al}, \mathrm{V}=5.70 \mathrm{~km} / \mathrm{s}$.

amorphous alloy reinforced bumper. We cannot find this melting zone in the hole of LY12 Al bumper. It may indicate higher temperature rise of projectile and bumper material during the penetration progress in amorphous alloy reinforced bumper at the velocity of $3.5 \mathrm{~km} / \mathrm{s}$.

There are a lot of craters on the rear wall of the Whipple shield. In order to compare the microstructures of craters in each test, only the largest crater on each rear wall has been studied.

Fig. 7 shows the microstructures at the bottom of each largest crater. The bottom of each crater is covered by smooth melting material with voids distributed in it. The reason for the formation of the voids is due to the gas sealed during the progress of fragmentation of the debris cloud while impacting against the rear wall. At the same impact velocity, the number of the voids with LY12 Al bumper is larger than that with amorphous alloy reinforced bumper, and the average size of the voids with LY12 Al bumper is also larger. As the impact velocity increases, the number and the average size of the voids becomes smaller no matter the front bumper material is LY12 Al or Fe-based amorphous alloy. The decrease of both the number and the size of the voids is due to the reduction of sealed gas amount. If we assume that the sealed gas amount is proportional to the area of collision cross section, and the area of collision cross section is related to the size of the impact fragment, the decrease of both the number and the size of the voids is due to decrease of the impact fragment size. Thus these microstructures may indicate that the largest fragment in the debris

Table 3

The characteristics of craters on the rear wall.

\begin{tabular}{lllll}
\hline Velocity $(\mathrm{km} / \mathrm{s})$ & 3.44 & 3.55 & 5.33 & 5.70 \\
\hline Front bumper material & $\mathrm{LY} 12 \mathrm{Al}$ & $\mathrm{Fe}_{77} \mathrm{Si}_{19} \mathrm{~B}_{4} / \mathrm{Al}$ & $\mathrm{LY} 12 \mathrm{Al}$ & $\mathrm{Fe}_{77} \mathrm{Si}_{19} \mathrm{~B}_{4} / \mathrm{Al}$ \\
Max crater diameter $(\mathrm{mm})$ & 6.5 & 4.0 & 3.0 & 3.0 \\
Max crater depth $(\mathrm{mm})$ & 1.0 & 0.7 & 1.0 & 1.0 \\
Main crater number & 1 & 0 & 0 & 0 \\
Medium crater number & 95 & 125 & 438 & 323 \\
Micro-crater number & 374 & 995 & 2337 & 3757 \\
\hline
\end{tabular}

cloud with amorphous alloy reinforced bumper is smaller than that with LY12 Al bumper at the same impact velocity.

Fig. 8 shows the microstructures near the edge of each largest crater. At the impact velocity of $3.5 \mathrm{~km} / \mathrm{s}$, smooth melting zone can be found in the crater with amorphous alloy reinforced bumper, but cannot be found in the crater with LY12 Al bumper. At the impact velocity of $5.5 \mathrm{~km} / \mathrm{s}$, smooth melting zone can be found in the crater with both bumper materials. These microstructures indicate that the crater with amorphous alloy reinforced bumper is totally covered by melting material at impact velocity of $3.5 \mathrm{~km} / \mathrm{s}$, while that with LY12 Al bumper is not totally covered. The possible reason is that the temperature of the debris cloud fragment with amorphous alloy reinforced bumper material is higher than that with LY12 Al bumper material, which is induced by higher temperature rise of projectile and bumper material during the penetration process in amorphous alloy reinforced bumper at the same impact velocity.

Fig. 9 shows some special patterns related to Fe-based amorphous alloy found at the bottom of the largest craters with amorphous alloy reinforced bumper. Because the rear wall doesn't contain Fe element, all the Fe element found in the crater comes from amorphous alloy coating in front bumper. As is illustrated in Fig. 9, the zone without Fe element seems smooth. But as the contents of Fe element increase, the microstructures become coarse.

\section{Analysis and discussion}

\subsection{Dimensional analysis}

In hypervelocity impact, different mechanical and thermal processes take place, such as plastic flow, fragmentation, spalling, melting and vaporization, and the parameters involved in these processes are numerous. So it is difficult to find out the key parameters that influenced the performances of the front bumpers in our tests. In order to simplify the analysis and reduce the number of parameters involved, a dimensional analysis was carried out. 

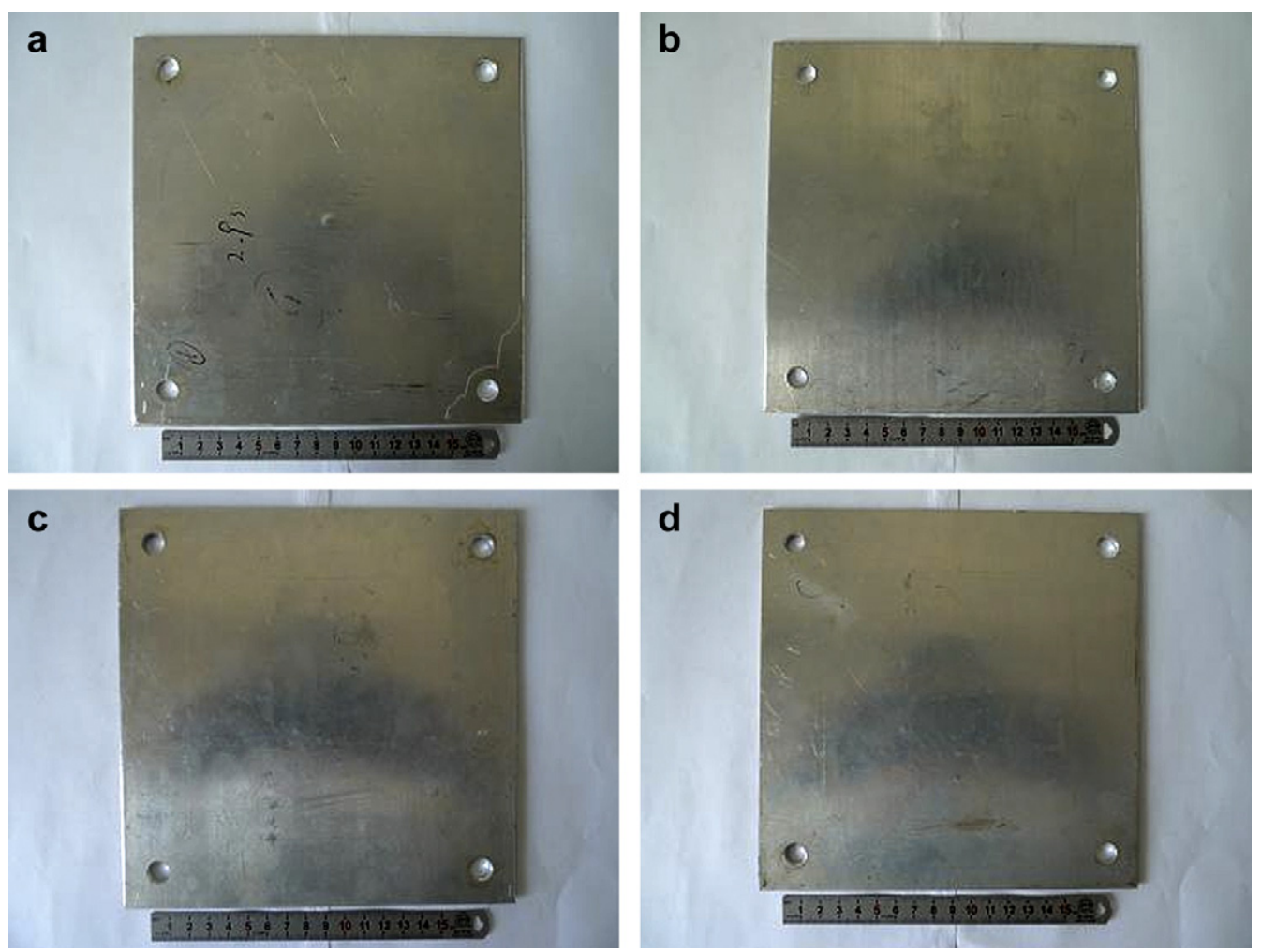

Fig. 4. Back side of the rear wall: (a) $\mathrm{LY} 12 \mathrm{Al}, \mathrm{V}=3.44 \mathrm{~km} / \mathrm{s}$; (b) $\mathrm{Fe}_{77} \mathrm{Si}_{19} \mathrm{~B}_{4} / \mathrm{Al}, \mathrm{V}=3.55 \mathrm{~km} / \mathrm{s}$; (c) $\mathrm{LY} 12 \mathrm{Al}, \mathrm{V}=5.33 \mathrm{~km} / \mathrm{s} ;(\mathrm{d}) \mathrm{Fe}{ }_{77} \mathrm{Si}{ }_{19} \mathrm{~B}_{4} / \mathrm{Al}$, $\mathrm{V}=5.70 \mathrm{~km} / \mathrm{s}$.

As is well known, the front bumper is used to break up the projectile and generate the debris cloud, so the characteristics of debris cloud can reflect the behavior of the front bumper. Previous works $[26,27]$ have shown that the two key characteristics of the debris cloud are: (1) the size of the largest central fragment; (2) an average median Martin diameter of the fine fragments resulting from shock-induced spall in the aluminum sphere and residing in the trailing portion of the debris cloud. As the largest central fragment can most possibly induce the complete penetration or detached spall of the rear wall, here we focus on the size of the largest fragment, assigned as $d_{\max }$. The smaller the $d_{\max }$ is, the better the front bumper behaves. The size of the largest fragment can be basically expressed as a function of all the parameters involved in the process that the front bumper breaks up the projectile

$d_{\max }=f\left(d_{p}, t_{p}, t_{c}, \rho_{p}, c_{p}, Y_{p}, C_{p} \theta_{p}, \rho_{c}, c_{c}, Y_{c}, C_{c} \theta_{c}, V\right)$

where $d_{p}$ is the diameter of the projectile, $t_{p}$ the thickness of the front bumper, $t_{c}$ the thickness of the coating of the front bumper, $p_{p}$ and $p_{c}$ the density of projectile and coating, $C_{p}$ and $C_{c}$ the acoustic speed of projectile and coating, $Y_{p}$ and $Y_{c}$ the strength of projectile and coating, $C_{p} \theta_{p}$ and $C_{c} \theta_{c}$ the product of specific heat and melting temperature of projectile and coating, which is the thermal energy per unit mass associated with bringing a body up to the phase change, and $V$ the impact velocity.

The material of the substrate is the same as the material of the projectile, so its parameters won't be list here. It is to be noted that

Table 4

The characteristics of bumps and perforations.

\begin{tabular}{lllll}
\hline Velocity $(\mathrm{km} / \mathrm{s})$ & 3.44 & 3.55 & 5.33 & 5.70 \\
\hline Front bumper material & $\mathrm{LY} 12 \mathrm{Al}$ & $\mathrm{Fe}_{77} \mathrm{Si}_{19} \mathrm{~B}_{4} / \mathrm{Al}$ & $\mathrm{LY} 12 \mathrm{Al}$ & $\mathrm{Fe}_{77} \mathrm{Si}_{19} \mathrm{~B}_{4} / \mathrm{Al}$ \\
Number of bumps & 20 & 20 & 54 & 50 \\
Number of perforations & 0 & 0 & 0 & 0 \\
\hline
\end{tabular}

the heat of fusion $\left(n_{p}\right.$ and $\left.n_{c}\right)$ is not list here, because $C \theta / n$ is approximately constant for many materials [28]. And the vaporization of the materials is also not taken to consideration, as the impact velocity is not very high in our tests. Only normal impact is considered here, so the impact angle of obliquity $\phi$ can be ignored.

All parameters in Eq. (1) involve three reference dimensions that are mass [M], length [L] and time [T]. According to Buckingham's $\pi$ theorem, $d_{p}, P_{c}$ and $V$ are chosen as the repeating variables, then Eq. (1) can be expressed by using dimensionless variables as Eq. (2)

$\frac{d_{\max }}{d_{p}}=g\left(\frac{t_{p}}{d_{p}}, \frac{t_{c}}{d_{p}}, \frac{\rho_{p}}{\rho_{c}}, \frac{V}{c_{p}}, \frac{\rho_{c} V^{2}}{Y_{p}}, \frac{\sqrt{C_{p} \theta_{p}}}{V}, \frac{V}{c_{c}}, \frac{\rho_{c} V^{2}}{Y_{c}}, \frac{\sqrt{C_{c} \theta_{c}}}{V}\right)$

And in our tests, each LY12 Al bumper can be interpreted as consisting of $0.15 \mathrm{~mm}$ LY12Al coating and $2.85 \mathrm{~mm}$ LY12 Al substrate, so the geometry configuration of each test is nearly the same. Besides, the projectile of each test is the same too. Then some of the non-dimensional variables in Eq. (2) are constant

$\frac{t_{t}}{d_{p}}=$ const, $\frac{t_{c}}{d_{p}}=$ const, $\frac{V}{c_{p}}=$ const, $\frac{\sqrt{C_{p} \theta_{p}}}{V}=$ const

so, Eq. (2) can be simplified to Eq. (3)

$\frac{d_{\max }}{d_{p}}=g\left(\frac{\rho_{p}}{\rho_{c}}, \frac{\rho_{c} V^{2}}{Y_{p}}, \frac{V}{c_{c}}, \frac{\rho_{c} V^{2}}{Y_{c}}, \frac{\sqrt{C_{c} \theta_{c}}}{V}\right)$

where $\rho_{p} / \rho_{c}$ is the density ratio, $\rho_{c} V^{2} / Y_{p}$ and $\rho_{c} V^{2} / Y_{c}$ are damage numbers [29] which can be interpreted as the ratio of impact pressure to the strength of the material, $V / C_{c}$ is the effective Mach number associated with inertia to compressibility, and $\sqrt{C_{c} \theta_{c}} / V$ is an energy ratio, whose numerator squared is associated with 

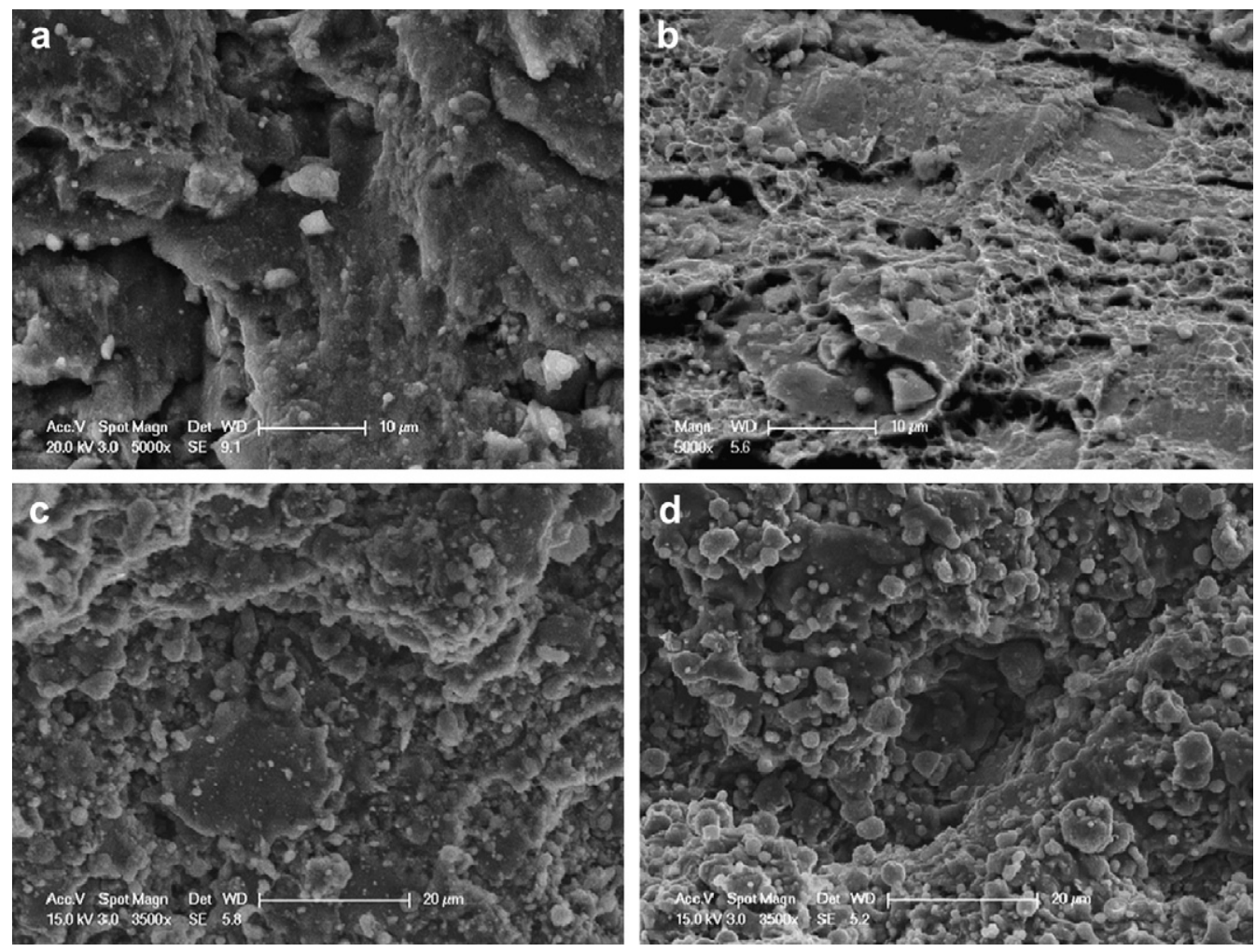

Fig. 5. Inner surfaces in the penetration holes: (a) $\mathrm{LY} 12 \mathrm{Al}, \mathrm{V}=3.44 \mathrm{~km} / \mathrm{s} ;(\mathrm{b}) \mathrm{Fe}_{77} \mathrm{Si}_{19} \mathrm{~B}_{4} / \mathrm{Al}, \mathrm{V}=3.55 \mathrm{~km} / \mathrm{s} ;$ (c) $\mathrm{LY} 12 \mathrm{Al}, \mathrm{V}=5.33 \mathrm{~km} / \mathrm{s}$; (d) $\mathrm{Fe}{ }_{77} \mathrm{Si}{ }_{19} \mathrm{~B}_{4} / \mathrm{Al}, \mathrm{V}=5.70 \mathrm{~km} / \mathrm{s}$.

thermal energy per unit mass that is needed to bring a body up to the phase change, and denominator squared is associated with the kinetic energy per unit mass.

Table 5 presents the material properties of LY12 aluminum alloy and the $\mathrm{Fe}_{77} \mathrm{Si}_{19} \mathrm{~B}_{4}$ amorphous alloy that is considered in Eq. (3). As shown in Table 5 , the acoustic speed of LY12 Al and $\mathrm{Fe}_{77} \mathrm{Si}_{19} \mathrm{~B}_{4}$ is nearly the same, but the density, the strength and the product of specific heat and melting temperature are quite different for both materials. So it indicates that the parameters $\rho_{c}, Y_{c}$ and $C_{c} \theta_{c}$ could be the major factors for different performance of the two bumpers. Compared with LY12 Al, the density and strength of $\mathrm{Fe}_{77} \mathrm{Si}_{19} \mathrm{~B}_{4}$ is larger, and the value of $C_{c} \theta_{c}$ is smaller. As the increase of coating density can increase the impact pressure, and the decrease of $C_{c} \theta_{c}$ makes it easier for melting of the coating material and faster that the coating strength decreases, the change of these parameters are helpful to the better performance of front bumper. But as the strength of coating increase, it will be harder for the coating to break up, and that may induce larger fragments in the debris cloud. In our test, the increase of the coating strength seems doing no harm to the behavior of the bumper. The possible reasons may be: (1) the thin thickness of $\mathrm{Fe}_{77} \mathrm{Si}_{19} \mathrm{~B}_{4}$ coating makes it impossible to form big fragments from coating material, and the largest central fragment most probably comes from the LY12 Al projectile or the LY12 Al Substrate; (2) the strength of the $\mathrm{Fe}_{77} \mathrm{Si}_{19} \mathrm{~B}_{4}$ coating may decrease a lot due to thermal softening of the material because of the smaller value of $C_{c} \theta_{c}$.

Hence, it can be concluded that higher density, lower specific heat and not very high melting temperature of the $\mathrm{Fe}_{77} \mathrm{Si}_{19} \mathrm{~B}_{4}$ amorphous alloy are helpful for the bumper to generate smaller fragments in debris cloud. And that may be the reason why the Febased amorphous alloy reinforced bumper makes better performance in our hypervelocity impact tests.

\subsection{Wave propagation}

The results of the hypervelocity impact tests have shown two important characteristics of the Fe-base amorphous alloy reinforced bumper: (1) it is more effective to break up the projectile
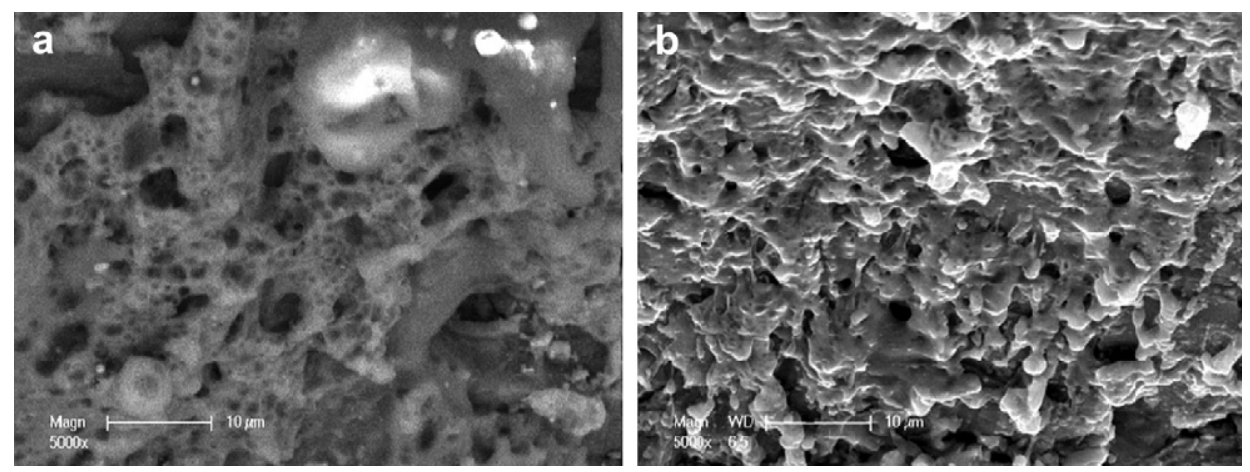

Fig. 6. Melting zone of the inner surface in the penetration hole. 

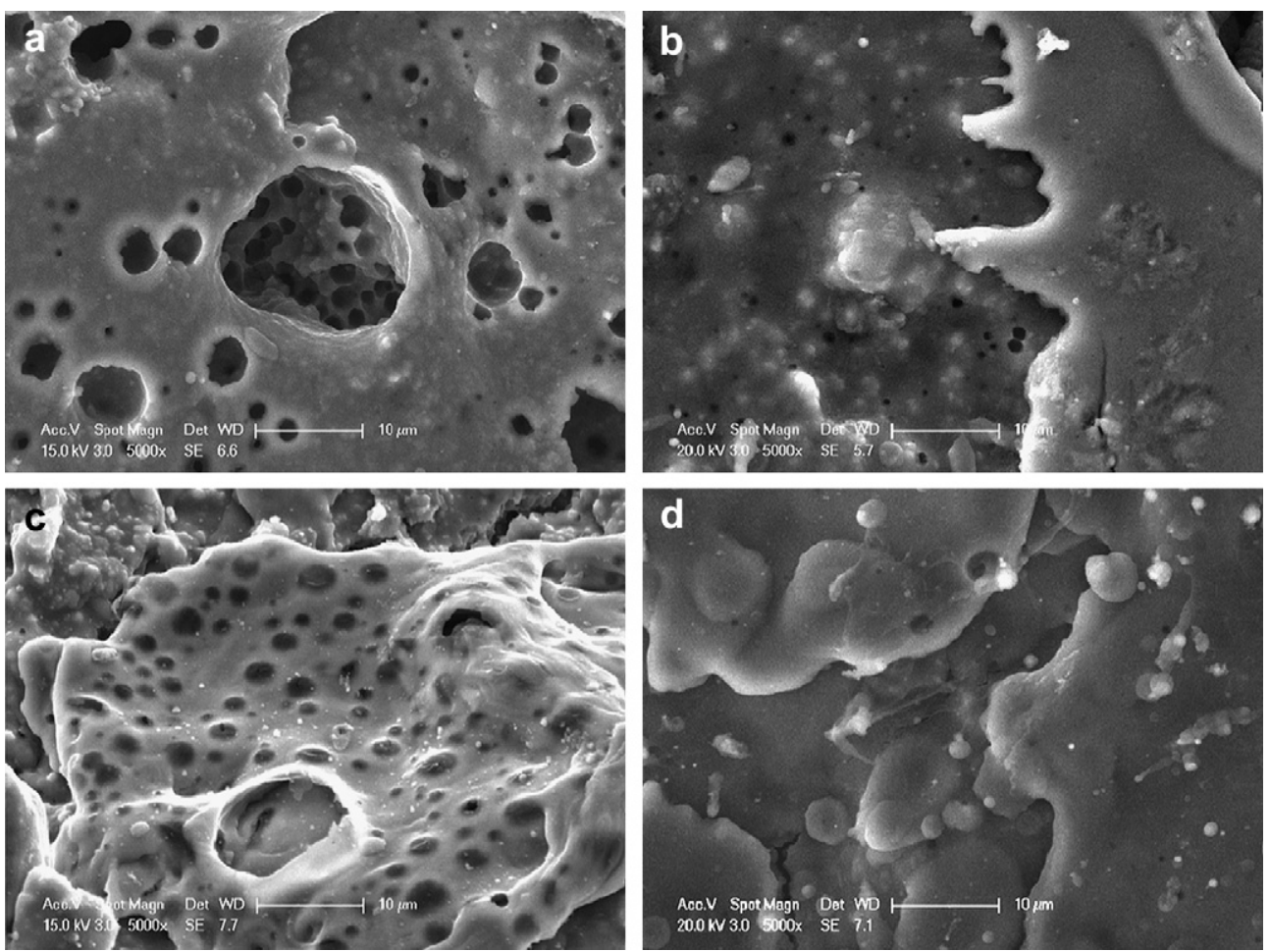

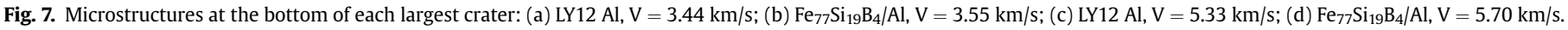

than LY12 Al bumper; (2) the temperature rise of projectile and bumper during the penetration process is higher than LY12 Al bumper. These can be explained by the physical process of debris cloud formation.

Following typical description of one-dimensional wave propagation in projectile and bumper produced by hypervelocity impact
[22,30,31], a schematic of the early stages of debris cloud formation is shown in Fig. 10.

Compared with monolithic LY12 Al bumper, the amorphous alloy reinforced bumper is a two-layer structure, so the wave propagation in this structure is somewhat different. After a sphere projectile impacts a two-layer bumper which consists of a coating
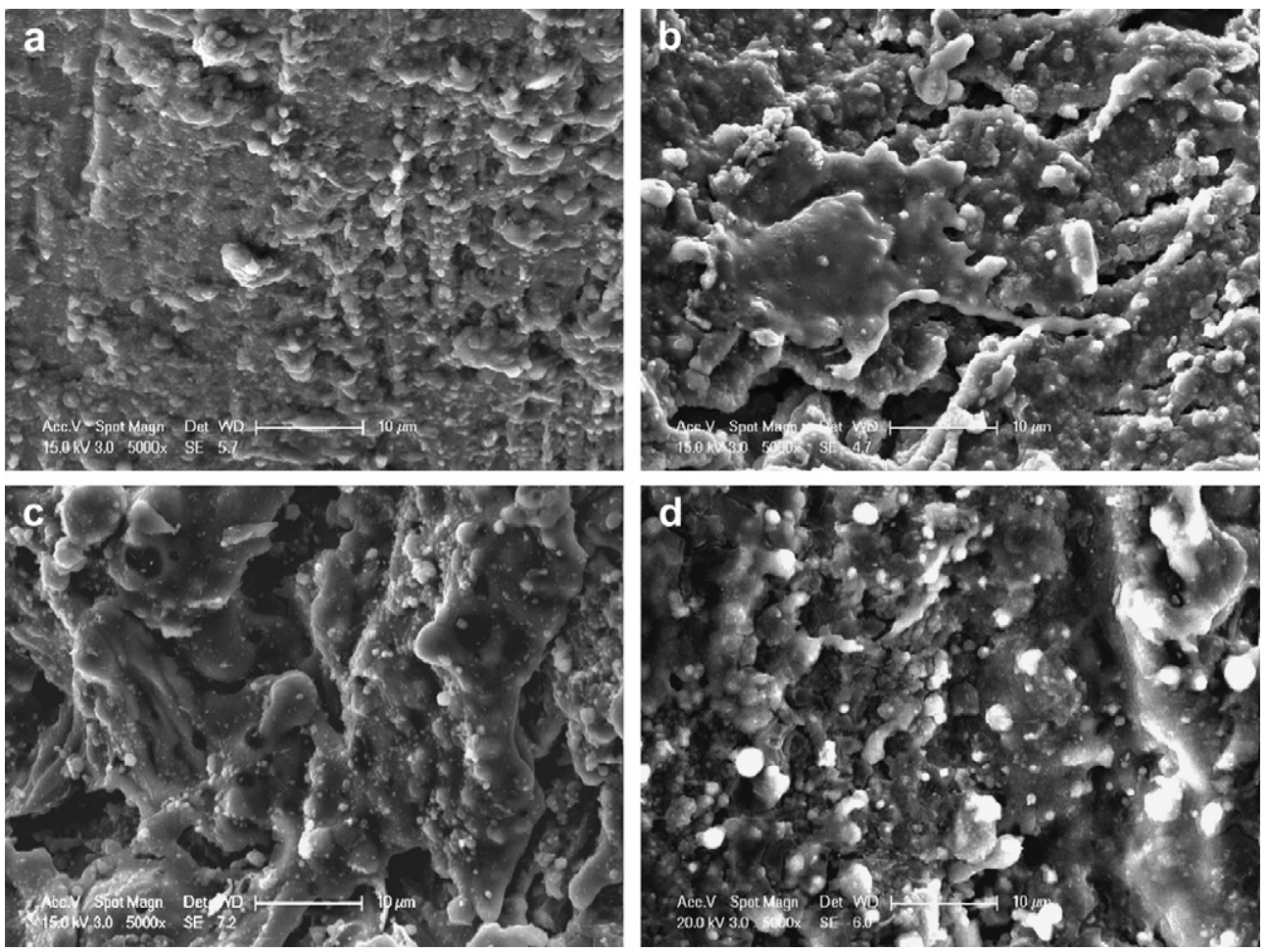

Fig. 8. Microstructures near the edge of each largest crater: (a) $\mathrm{LY} 12 \mathrm{Al}, \mathrm{V}=3.44 \mathrm{~km} / \mathrm{s}$; (b) $\mathrm{Fe}_{77} \mathrm{Si}_{19} \mathrm{~B}_{4} / \mathrm{Al}, \mathrm{V}=3.55 \mathrm{~km} / \mathrm{s} ;$ (c) $\mathrm{LY} 12 \mathrm{Al}, \mathrm{V}=5.33 \mathrm{~km} / \mathrm{s} ;(\mathrm{d}) \mathrm{Fe}{ }_{77} \mathrm{Si}_{19} \mathrm{~B}_{4} / \mathrm{Al}, \mathrm{V}=5.70 \mathrm{~km} / \mathrm{s}$. 

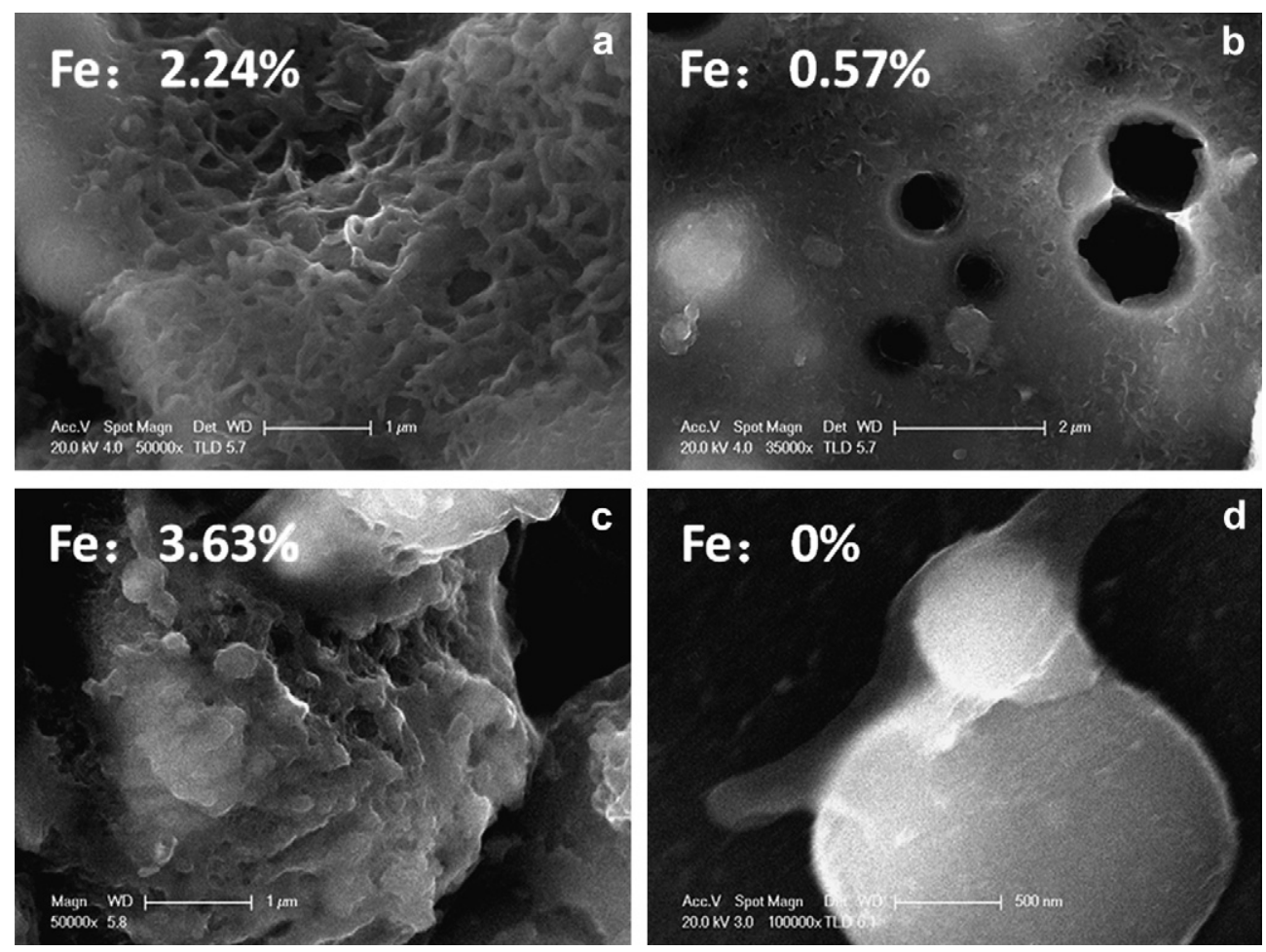

Fig. 9. Special patterns related to Fe-based amorphous alloy: (a)(b) $\mathrm{Fe}_{77} \mathrm{Si}_{19} \mathrm{~B}_{4} / \mathrm{Al}, \mathrm{V}=3.55 \mathrm{~km} / \mathrm{s}$; (c)(d) $\mathrm{Fe}_{77} \mathrm{Si}_{19} \mathrm{~B}_{4} / \mathrm{Al}, \mathrm{V}=5.70 \mathrm{~km} / \mathrm{s}$.

Table 5

Material properties of $\mathrm{LY} 12 \mathrm{Al}$ and $\mathrm{Fe}_{77} \mathrm{Si}_{19} \mathrm{~B}_{4}$.

\begin{tabular}{llllll}
\hline Material & $\begin{array}{l}\text { Density } \\
\left(\mathrm{g} / \mathrm{cm}^{3}\right)\end{array}$ & $\begin{array}{l}\text { Strength } \\
(\mathrm{MPa})\end{array}$ & $\begin{array}{l}\text { Acoustic } \\
\text { speed }(\mathrm{km} / \mathrm{s})\end{array}$ & $\begin{array}{l}\text { Specific heat } \\
(\mathrm{J} /(\mathrm{g} * \mathrm{~K}))\end{array}$ & $\begin{array}{l}\text { Melting } \\
\text { temperature(K) }\end{array}$ \\
\hline $\mathrm{LY} 12 \mathrm{Al}$ & 2.78 & 340 & $6.32^{\mathrm{a}}$ & $0.90^{\mathrm{a}}$ & $933^{\mathrm{a}}$ \\
$\mathrm{Fe}_{77} \mathrm{Si}_{19} \mathrm{~B}_{4}$ & $7.2^{\mathrm{b}}$ & $2980^{\mathrm{c}}$ & $5.94^{\mathrm{d}}$ & $0.45^{\mathrm{d}}$ & $1198^{\mathrm{e}}$ \\
\hline
\end{tabular}

${ }^{\text {a }}$ From aluminum.

${ }^{b}$ Calculated from atom ratio.

${ }^{c}$ From $\mathrm{Fe}_{77} \mathrm{Ga}_{3} \mathrm{P}_{9.5} \mathrm{C}_{4} \mathrm{~B}_{4} \mathrm{Si}_{2.5}$.

${ }^{\mathrm{d}}$ From steel.

e From $\mathrm{Fe}_{77} \mathrm{Ga}_{5} \mathrm{P}_{12} \mathrm{C}_{4} \mathrm{~B}_{4}$. and a substrate at a velocity of $V_{0}$, two shock waves $\mathrm{S} 1$ and $\mathrm{S} 2$ and two rarefaction waves $\mathrm{R} 1$ and $\mathrm{R} 2$ are generated at the same time. For the bumper is a two-layer structure, there are two interfaces which are projectile-coating interface and coating-substrate interface. When shock wave S2 reaches the coating-substrate interface, a reflection wave $\mathrm{R} 3$ and a transmission wave $\mathrm{T} 1$ take place. In our tests, the acoustic impedance of substrate is lower than that of coating, so R3 is a rarefaction wave. After R3 reaches the projectile-bumper interface, the rarefaction wave $\mathrm{R} 4$ is transmitted and continues to propagate into the projectile, one of the following situations may occur: (1) Shock wave S1 is reflected as a rarefaction wave R6 from the free boundary of projectile, then R4 interacts with R6 forming tensile region. In this case, the whole projectile is
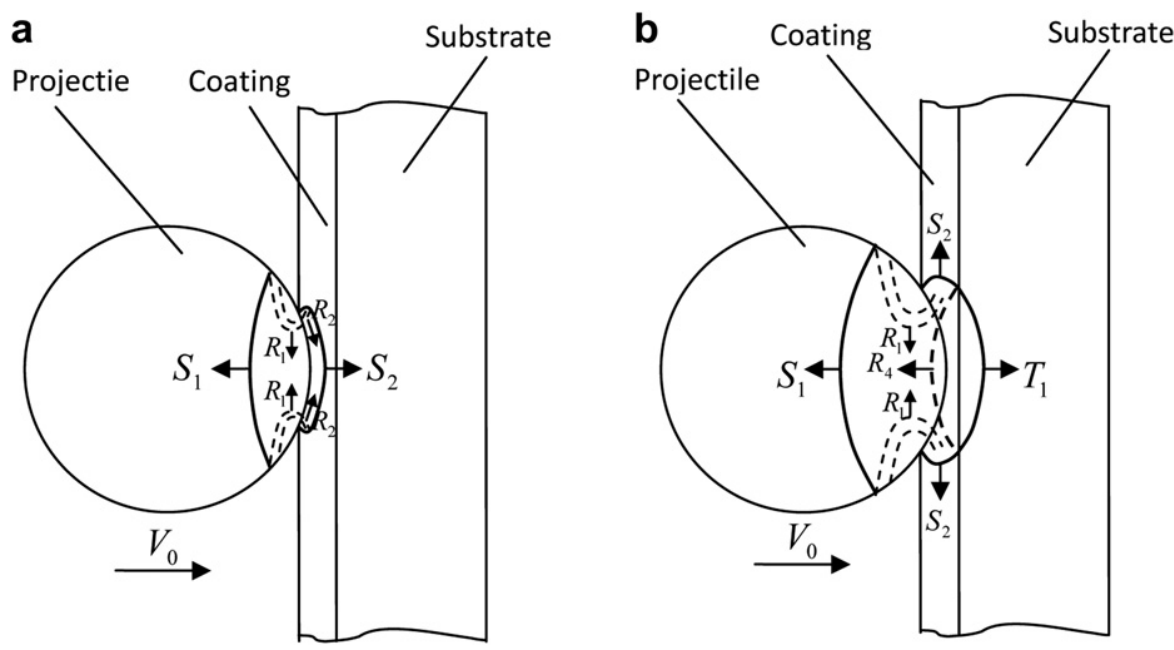

Fig. 10. Wave propagation in the projectile and bumper. 
Table 6

Parameters used in the calculation.

\begin{tabular}{lllll}
\hline Material & $C_{0}$ & $\mathrm{k}$ & $\rho_{0}$ & $\Gamma_{0}$ \\
\hline $\mathrm{LY} 12 \mathrm{Al}$ & 5.328 & 1.338 & 2.785 & 2.00 \\
$\mathrm{Fe}_{77} \mathrm{Si}_{19} \mathrm{~B}_{4}$ & $3.574^{\mathrm{a}}$ & $1.920^{\mathrm{a}}$ & $7.2^{\mathrm{b}}$ & $1.69^{\mathrm{a}}$ \\
\hline
\end{tabular}

a From steel.

b Calculate from atom ratio.

compressed more heavily than that with Al bumper. (2) Rarefaction wave $\mathrm{R} 4$ catches up with $\mathrm{S} 1$ creating an attenuating wave, which is reflected as a rarefaction wave from the free boundary of projectile later. In this case, only part of the projectile is compressed more heavily.

When transmission wave $\mathrm{T} 1$ reaches the free surface of bumper, it is also reflected as a rarefaction wave. As these rarefaction waves interact, regions of tension form. If the net tension stress exceeds the material strength, fracture will occur. The fracture of the projectile and target can be interpreted as a multiple-spalling phenomenon, and particle size of the debris cloud can be influenced by two important factors [22]: 1) the strength of the shock waves which determine the magnitude of the rarefaction waves, 2) the tensile strength of the projectile and target materials, which can be degraded by the heating of the material caused by the shock waves.

The Fe-based amorphous alloy coating used in our test can affect the two factors. Due to the higher acoustic impedance of Fe-based amorphous alloy, the shock pressures of S1 and S2 with amorphous alloy reinforced bumper material are higher than that with LY12 Al bumper material, and the higher amplitude of shock waves induces more severely heating of the material, then the strength of the material is degraded more. Thus, the particle size of the debris cloud that is produced by amorphous alloy reinforced bumper is smaller than that produced by LY12 Al bumper.

Based on the simple one-dimensional consideration [22,32], the amplitude of the shock waves S1 and S2 was calculated, and the max temperature rise in the projectile has been estimated. It is to be noted that there are two dissipation processes that induce the heating of material. One is the plastic deformation of material, another is a consequence of entropy production in the non-linear shock compression event. As the entropy production in the non-linear shock compression event plays a key role in the material heating [33], the contribution of plastic deformation is neglected here.

Table 6 presents the parameters needed in the calculation. $C_{0}$ and $k$ are the coefficients in the Rankine-Hugoniot relationship:

$u_{s}=c_{0}+k u_{p}$

$\rho_{0}$ and $\Gamma_{0}$ are the coefficients of the Mie-Gruneisen EOS:

$P=P_{H}+\rho \Gamma\left(E-E_{H}\right)$

where it is usually assumed that:

$\Gamma=\Gamma_{0} \rho_{0} / \rho$

Table 7

Calculation results.

\begin{tabular}{|c|c|c|c|c|}
\hline \multirow{2}{*}{$\frac{\text { Impact velocity }}{\text { Coating material }}$} & \multicolumn{2}{|l|}{$3.5 \mathrm{~km} / \mathrm{s}$} & \multicolumn{2}{|l|}{$5.5 \mathrm{~km} / \mathrm{s}$} \\
\hline & LY12 Al & $\mathrm{Fe}_{77} \mathrm{Si}_{19} \mathrm{~B}_{4}$ & LY12 Al & $\mathrm{Fe}_{77} \mathrm{Si}_{19} \mathrm{~B}_{4}$ \\
\hline Shock wave strength(GPa) & 37.4 & 52.8 & 69.0 & 101 \\
\hline $\begin{array}{l}\text { Residual internal energy of } \\
\text { projectile }(\mathrm{MJ} / \mathrm{kg})\end{array}$ & 0.23 & 0.43 & 0.68 & 1.19 \\
\hline $\begin{array}{l}\text { Temperature rise of } \\
\text { projectile }(\mathrm{K})\end{array}$ & 240 & 429 & $\begin{array}{l}\text { Incipient } \\
\text { melt }\end{array}$ & $\begin{array}{l}\text { Complete } \\
\text { melt }\end{array}$ \\
\hline
\end{tabular}

In our calculation, Mie-Gruneisen EOS has been adopted due to the not very high impact velocity in our tests so that no vaporization of material would take place. For lack of coefficients of the Rankine-Hugoniot relation and Mie-Gruneisen EOS for $\mathrm{Fe}_{77} \mathrm{Si}_{19} \mathrm{~B}_{4}$ amorphous alloy [34], coefficients of steel were used as a rough estimate.

Table 7 presents the results of the calculation. Compared with monolithic LY12 Al bumper, the shock wave strength and material temperature rise in the projectile are obviously higher at the same impact velocity when Fe-based amorphous alloy reinforced bumper is used. That is the reason for the better performance of Febase amorphous alloy reinforced bumper.

\section{Conclusion}

A new Whipple shield structure which consists of an amorphous alloy reinforced bumper and an $\mathrm{LY} 12 \mathrm{Al}$ rear wall is proposed in this paper. In order to evaluate the performance of this new Whipple shield, hypervelocity impact tests have been performed on the new Whipple shield and the traditional Whipple shield at different impact velocities of $3.5 \mathrm{~km} / \mathrm{s}$ and $5.5 \mathrm{~km} / \mathrm{s}$. Damages including penetration hole in the front bumper and craters on the rear wall are carefully studied, and it is indicated the protective capability of new Whipple shield is higher than the traditional one, especially at lower impact velocity of $3.5 \mathrm{~km} / \mathrm{s}$. Result of a dimensional analysis shows that the higher density, lower specific heat and not very high melting temperature of Fe-based amorphous alloy are the possible reason for better performance of the amorphous alloy reinforced bumper. Wave propagation in the projectile and bumper is discussed, and the shock wave strength and temperature rise in the material are evaluated. And it is shown that the amorphous alloy reinforced bumper can generate higher shock pressures and induce higher temperature rise in the projectile which is a major advantage of the Fe-based amorphous alloy. For the difficulties in fabricating amorphous reinforced bumpers, the number of the present experiments is very limited. However, our preliminary work shows some positive indications that the amorphous alloy reinforced bumper may be more effective to fragment the projectile, and this new Whipple shield structure proposed in the paper may offer higher protection level than the traditional one.

\section{Acknowledgments}

Financial support is from the NSFC (Grants Nos.10872206, $10725211,11021262,11002144$, and 11132011), the National Natural Science Foundation of China-NSAF. Grant No: 10976100, the National Key Basic Research Program of China (Grant No. 2009CB724401).

\section{References}

[1] Whipple FL. Meteorites and space travel. Astronomical Journal 1947;52. 131-131.

[2] Schonberg WP, Bean AJ. Hypervelocity impact response of aluminum multiwall structures. Acta Astronautica 1991;25:363-73.

[3] Christiansen EL, Kerr JH. Ballistic limit equations for spacecraft shielding. International Journal of Impact Engineering 2001;26:93-104.

[4] Christiansen EL, Crews JL, Williamsen JE, Robinson JH, Nolen AM. Enhanced meteoroid and orbital debris shielding. International Journal of Impact Engineering 1995;17:217-28.

[5] Cour-Palais BG, Crews JL. A multi-shock concept for spacecraft shielding. International Journal of Impact Engineering 1990;10:135-46.

[6] Schonberg WP, Compton LE. Application of the NASA/JSC Whipple shield ballistic limit equations to dual-wall targets under hypervelocity impact. International Journal of Impact Engineering 2008;35:1792-8.

[7] Buyuk M, Kurtaran H, Marzougui D, Kan CD. Automated design of threats and shields under hypervelocity impacts by using successive optimization methodology. International Journal of Impact Engineering 2008;35:1449-58. 
[8] Zhang QM, Chen Y, Huang F, Long R. Experimental study on expansion characteristics of debris clouds produced by oblique hypervelocity impact of LY12 aluminum projectiles with thin LY12 aluminum plates. International Journal of Impact Engineering 2008;35:1884-91.

[9] Cour-Palais BG. Hypervelocity impact in metals, glass and composites. International Journal of Impact Engineering 1987;5:221-37.

[10] Robinson JH, Nolen AM. An investigation of metal matrix composites as shields for hypervelocity orbital debris impacts. International Journal of Impact Engineering 1995;17:685-96.

[11] Tamura H, Mutou Y. Quantitative analysis of debris clouds from SiC-fiberreinforced silicon nitride bumpers. International Journal of Impact Engineering 2005;31:1192-207.

[12] Destefanis R, Schäfer F, Lambert M, Faraud M. Selecting enhanced space debris shields for manned spacecraft. International Journal of Impact Engineering 2006;33:219-30.

[13] Ryan S, Hedman T, Christiansen EL. Honeycomb vs. foam: evaluating potential upgrades to ISS module shielding. Acta Astronautica 2010;67:818-25.

[14] Dai LH, Bai YL. Basic mechanical behaviors and mechanics of shear banding in BMGs. International Journal of Impact Engineering 2008;35:704-16.

[15] Jiang MQ Dai LH. On mechanical properties of metallic glass and its liquid vitrification characteristics. Structural Integrity and Failure 2008;41-42: 247-52.

[16] Jiang MQ, Ling Z, Meng JX, Dai LH. Energy dissipation in fracture of bulk metallic glasses via inherent competition between local softening and quasicleavage. Philosophical Magazine 2008;88:407-26.

[17] Lewandowski JJ, Lowhaphandu P. Effects of hydrostatic pressure on the flow and fracture of a bulk amorphous metal. Philosophical Magazine A 2002;82: 3427-41.

[18] Conner RD, Rosakis AJ, Johnson WL, Owen DM. Fracture toughness determination for a beryllium-bearing bulk metallic glass. Scripta Materialia 1997;37: 1373-8.

[19] Kim HJ, Lee JK, Shin SY, Jeong HG, Kim DH, Bae JC. Cu-based bulk amorphous alloys prepared by consolidation of amorphous powders in the supercooled liquid region. Intermetallics 2004;12:1109-13.
[20] Inoue A, Shen BL, Chang CT. Fe- and Co-based bulk glassy alloys with ultrahigh strength of over $4000 \mathrm{MPa}$. Intermetallics 2006;14:936-44.

[21] Wang WH, Dong C, Shek CH. Bulk metallic glasses. Materials Science \& Engineering R-Reports 2004;44:45-89.

[22] Anderson CE, Trucano TG, Mullin SA. Debris cloud dynamics. International Journal of Impact Engineering 1990;9:89-113.

[23] Bjork RL. The physics of hypervelocity lethality. International Journal of Impact Engineering 1987;5:129-54

[24] Wei SC, Xu BS, Wang HD, Jin G, Lv H. Comparison on corrosion-resistance performance of electro-thermal explosion plasma spraying FeAl-based coatings. Surface \& Coatings Technology 2007;201:5294-7.

[25] Tamura H, Konoue M, Sawaoka AB. Zirconium boride and tantalum carbide coatings sprayed by electrothermal explosion of powders. Journal of Thermal Spray Technology 1997;6:463-8.

[26] Grady DE. Comparison of hypervelocity fragmentation and spall experiments with Tuler-Butcher spall and fragment size criteria. International Journal of Impact Engineering 2006;33:305-15.

[27] Piekutowski A. Formation and description of debris clouds produced by hypervelocity impact. NASA CR-4707; 1996.

[28] Westine PS, Mullin SA. Scale modeling of hypervelocity impact. International Journal of Impact Engineering 1987;5:693-701.

[29] Johnson W. Impact strength of materials. London: Edward Arnold; 1972.

[30] Maiden CJ, McMillan AR. An investigation of the protection afforded a spacecraft by a thin shield. Aiaa Journal 1964;2:1992-8.

[31] Yew CH, Grady DE, Lawrence RJ. A simple model for debris clouds produced by hypervelocity particle impact. International Journal of Impact Engineering 1993;14:851-62.

[32] Ejork RL, Olshaker AE. The role of melting and vaporization in hypervelocity impact. MEMORANDUMRM RM-3490-PR; 1965.

[33] Zhang OM, Tan OM, Zhang DL, Cheng CM. Melting effects of aluminum dualsheet structure in hypervelocity impact. Acta Mechanica Sinica 1995;27: 257-66.

[34] Trexler MM, Thadhani NN. Mechanical properties of bulk metallic glasses Progress in Materials Science 2010;55:759-839. 